\section{COLDING ON THE LAWS OF CURRENTS IN ORDINARY CONDUITS AND IN THE $S E A$}

[I SEND to NATURE for translation the abstract (in French) appended, according to a most excellent custom, to Colding's great paper in the Copenhagen Transactions. The subject is one of especial interest at the present time, though, of course, everything written by such a man is deserving of careful attention. Those in particular who met the genial Dane at the British Association will be glad to have in a compact form his views on a question which has given rise to much discussion, and which is of very great practical importance. - P. G. TAIT]

I PRESENTED in 1863 to the Scientific Society, and some months later to the Congress of Scandinavian Naturalists at Stockholm, a short exposition of my researches on the motion of fluid bodies, on which I had been occupied for several years, and the results of which appeared to me worthy of being submitted to the Society.

The characteristic of this work is that it does not suppose, like previous works of the same kind, that all the parts of a current are endowed with the same rapidity; for it owes, in fact, its existence to my conviction that this mode of looking at the subject can only lead in exceptional cases to exact results. My researches are based on the different motions assumed by the liquid threads or elements of the currents, and are supported by the well-known fact that any body, and consequently any portion of a fluid, can only move with a constant rapidity when the accelerating force is equal to the resistance.

In the case of a fiuid flowing by virtue of its own weight over a plane surface which opposes a resistance to the motion of the water, it was easy to determine how this motion varies with the depth, when the rapidity of the current is constant in all its parts; and, by pursuing this train of thought, I was led to the law of the variation of the rapidity with the depth, when the current moves in a cylindrical conduit with circular section, completely filled with the liquid. These researches are of greater interest from the circumstance that the laws at which $\mathrm{I}$ have in this manner arrived from theoretical considerations, are confirmed by the experiments which have recently been carried out in France by Capt. Boileau and Inspector. General Darcy. These laws of the motion of water may be expressed by the formula

$$
(V-v)^{2}=K_{0}^{2} \frac{h}{l} x^{3}
$$

where $V$ is the rapidity of the first elements of the current, the motion of which is the most rapid, $v$ the rapidity at the depth $x, \frac{h}{l}$ the fall per foot of the water, and $K_{0}^{2}$ a magnitude which depends entirely on the nature and dimensions of the conduit, on the depth of the current, \&c. The theory shows besides that the laws of the motion of water on a level surface are included in the general law of the motion of water on a cylindrical surface, when the radius of the cylinder is supposed infinite.

Darcy, who has experimentally established the formula given above for cylindrical conduits, endeavoured, at the same time, to determine $K_{0}^{2}$ by means of certain experiments performed with four different kinds of pipes, and found that $K_{0}^{2}$ was inversely proportional to the square of the radius of the conduit. It resulted, according to the theory, that, for level conduits, $K_{0}^{2}$ should be in the same manner in an inverse ratio to the square of the depth of the current. But two series of experiments performed by Boileau with level conduits led, on the contrary, to the supposition that $K_{0}^{2}$ was inversely proportional simply to the depth of the current. There was thus a want of agreement between the results of the two experiments, and the point was to discover which of these two hypotheses was correct. Several circumstances leading me to believe that Darcy's theory could not be exact, I took as my starting point the experiments of Boileau, and considered $K^{2}$ as inversely proportional to the depth of the current, which I did with the less scruple since this hypothesis agreed almost as well with Darcy's experiments as with his own. I pursued, therefore, my researches on this basis, and, after many difficulties, arrived at results which, on the whole, were so entirely in accordance with experiments that I could not suppose the possibility of Boileau's hypothesis being inexact. It was only afterwards, when I approaclied the study of marine currents, that new difficulties constantly arose, which I endeavoured at first to overcome, but which became day by day more insur. mountable, until at last there was nothing left but to doubt the correctness of my calculations, since they led to results which were in obvious contradiction to facts.

The theory then was shown to be inexact; but since in so large a number of cases it was evidently in agreement with experiment, I attempted by a variety of means to discover the error which I must have committed; still all my attempts were unattended with result, and I was on the point of abandoning the resolution of the problem to which $I$ had already devoted so much time, when the idea struck me of examining what would happen if I rejected Boileau's determination of $K_{0}{ }^{2}$, and adopted Darcy's hypothesis, although it still appeared to me impossible; when I found, with as much delight as surprise, that it removed not only the great difficulties which I had up to that time en. countered, but also all the contradictions which had occurred to me as an inevitable consequence of that hypothesis, and from that moment the results of the calculations showed themselves to be entirely in the most perfect accordance with what exists in nature.

The circumstance that the experiments of Darcy are almost as satisfactory whether $\frac{x}{K_{0}^{2}}$ is supposed to be proportional to the first or to the second power of the depth of the currents, made me think that the reality would be still more nearly approached by expressing this magnitude by a binomial of the first and second degree, and this was completely confirmed by facts. In determining the constants of the binomial according to the results of Darcy's experiments, I found the law of the motion of the water in cylindrical pipes with a radius $R$, with a coefficient of resistance $m$, and a rapidity $v_{0}$ at the surface of the conduit, may be represented by the formula

$V-v=6.8 \sqrt{m} \times v_{0} \times\left(\frac{x}{R}\right)^{\frac{3}{2}} \sqrt{\frac{1177 R}{62.5+1177 R}}$

$V$ being the rapidity next the axis, to which corresponds $x=0$. This formula may be applied equally to the movement of water in level conduits, if by $R$ is designated the depth of the current ; only the coefficient then becomes $\frac{6.8}{\sqrt{ }} \frac{1}{2}=4.8$, instead of 6.8 .

This formula shows, among other things, that the ratio $\frac{v}{V}$ which corresponds to any point in a given conduit entirely filled by the current, is entirely independent of the rapidity of the current, a fact which Darcy's experiments confirm in a remarkable manner. This relation furnishes us besides with the means of determining the value of the coefficient of resistance $n$ for different kinds of pipes which were employed by Darcy, and it is thus found that for
Old pipes
$m=$ from 0.0120 to 0.0080
New pipes
$m=$ from 0.0050 to 0.0033
New varnished pipes. $\quad m=$ from 0.0033 to 0.0025

values which are altogether independent of the diameter of the conduit. For level wooden couduits, it is found, according to the experiments of Boileau, that $m=0$ or 60 to $0 \cdot 0090$, while the resistance of the air, according to the same author, corresponds to $m=0.0003$ to 0.0002

Inspector-General Darcy has unfortunately died, but the researches on currents which he commenced were continued by the French engineer Bazin, who published in 1865 a great work on the results of a considerable number of experimentsmarried on with conduits of very different kinds.

However interesting otherwise these researches may be, they do not display either the powers of observation or the grandeur of conception which distinguish the works of Darcy. Among those experiments which are of the greatest interest, there are some begun by Darcy and finished by Bazin, such as researches into the motion of water in rectangular conduits, where the rapidity is determined in 45 points symmetrically distributed. The result for these, as for circular conduits, is that the ratio $\frac{v}{V}$ is independent of the absolute rapidity of the current, and if the results of experiment on the motion of water in level conduits are compared with those given by the theoretic formula, it will be found that these last agree so completely with experiment, that the difference between the calculated and observed rapidities, in each of the 45 points mentiuned above, falls within the limit of errors of observation. This agreement is especially remarkable in the case of the conduit which Darcy employed in 1857 for the carrying out 
of his researches. In 1859 Bazin undertook similar experiments with a small rectangular conduit; but he did not make so great a number of experiments, and his errors of observation are larger than those of Darcy. In determining the coefficients of resistance of these conduits, it was found that for those of Darcy $m=0104$, while for those of Bazin it rose to 0.0180.

Bazin performed a considerable number of experiments on the motion of water in open conduits, and thought himself com. pelled to admit that the laws of this motion are essentially different from those which relate to perfectly full conduits; but he is certainly in error.

The results of a considerable number of ancient measures of currents are in existence, which Bruning undertook, towards the close of last century, in different rivers-namely, the Rhine, Waal, \&c. They were performed with much care; but, as might be foreseen, are nevertheless very defective. They deserve, however, to attract attention, partly because the rapidity was determined, for every section of the current, at distances of six inches from the surface to the bottom, in a series of perpendiculars, the imperfections which the measurement of the rapidity presents losing thus much of their importance; partly and especially. because the currents examined by Bruning were of a depth which reached 23 feet. In applying this theory to these currents, and especially in determining the constants of the formulæ with the aid of Bruning's measurements, it was found that the observed and calculated rapidities are for all depths as accordant as could be desired; and this agreement furnishes a new proof of the exactness of the theory. The coefficient of resistance $n$, calculated according to Bruning's measurements, varies between 0.0250 and 0.0080 , with a mean of 0.0160 ; and as the resistance at the depth of these currents must doubtless approach that which a marine current experiences in flowing over a mass of water placed beneath it, and which does not participate in the motion, I have a right to believe that the extreme value $m=0.0250$ corresponds nearly to the resistance which currents meet with when flowing freely in the sea.

After having in this manner assured myself that the preceding theory agrees with experiment wherever it has been tried, I endeavoured to determine the laws of the motion of water in currents of variable rapidity. In considering the simplest case of this kind, that, namely, in which the conduit is a level surface (I had already treated this case by the old theory), it was found that the laws of currents, according to the new theory, are entirely in agreement with the facts observed in nature; and consequently this theory may be regarded as giving the explanation of all permanent currents.

Having thus shown that this theory of the movement of fluid bodies accounts satisfactorily for all the phenomena, I shall now, from this as a stand-point, give a review of my recent researches upon ocean currents. The currents which more particularly demand our attention here are those of the North Atlantic, especially the Gulf Stream and the Polar Currents.

The Gulf Stream issues, as we know, from the Gulf of Mexico, but it is possible to follow its course across the Carribean Sea, where passing between the Antilles, it arrives from the Atlantic, and afterwards flows to the north-west at the rate of $\frac{1}{4}$ mile an hour until it enters the Gulf of Mexico. From this Gulf the Gulf Stream takes an easterly course towards the Bahamas along the north coast of Cuba ; but, after rounding Florida, it bends northwards, and passes between the latter and the Bahamas, in the channel which separates Florida Cape from the Islets of Bemini; here the current has a speed of I mile per hour, a breadth of 8 miles, and a depth of 250 fathoms. From the channel of Bemini the Gulf Stream proceeds directly north wards at a rate which decreases gradually from $6 \frac{1}{3}$ feet per second at Bemini to 4 feet at St Augustine; the distance between these two points being about 70 miles, during which the breadth of the current increases from 8 miles to $\mathrm{rI} \frac{\mathrm{s}}{4}$. From St. Augustine to the Bay of New York the Gulf Stream takes a north-easterly course, parallel with the land, and conterminous with a cold current which flows from the north to the south between the stream and the American coast. In this part of its course it continues to increase in breadth from $11 \frac{3}{4}$ miles at St. Augustine to $31 \frac{3}{4}$ at New York; meanwhile its speed decreases from 4 feet to $2 \frac{1}{2}$ per second. The depth of the sta along the course of the current is many hundred fathoms, and the distance between St. Augustine and New York is 180 miles. On quitting the Bay of New York, the Gulf Stream takes an E.N.E. direction to the south of Newfoundland, skirting the cold current, which goes down to southwest as far as New York, following the east coast of Newfound. land. By the time the Gulf Stream, after a course of 200 miles, reaches the south of Newfoundland, it has attained a breadth of about 80 miles, while its speed is only 2 feet per second; but the current continues to run in the same direction towards Europe for other 300 miles, with a speed which is from 2 feet to 0.6 feet, and a breadth increasing from 80 up to 200 miles. The Gulf Stream, when it has attained a distance of 750 miles from Bemini, separates into two branches, the one proceeding southwards towards the coast of Africa, at a speed of 0.6 feet per second, the other taking a northerly course towards. Iceland, along the shores of the British Islands, and running about 200 miles, at a rate which decreases from 0.6 to 0.3 feet per second, the breadth of the current meanwhile increasing from 100 to I05 miles. When the stream reaches the neighbourhood of Iceland, it sends off a branch which skirts the south coast of that island, afterwards taking a direction north-west towards the Polar current of the east coast of Greenland, which it seems partly to follow in its march southwards. As to the main stream, it inclines to the east after passing the extreme north of Scotland, and then runs to the north-east, along the west coast of Norway, until it ends its wanderings in the Icy Sea.

As to the Polar Current we feel authorised to mention the following statements :-From the region of the Icy Sea, the most northerly of which we have any knowledge, from the neighbourhood of Spitzbergen about the 8oth degree of $\mathrm{N}$. latitude, there descends to the south-west a great polar current loaded with floating ice. It reaches the coast of Greenland at about $70^{\circ} \mathrm{N}$. latitude, and follows it as far as Cape Farewell; its breadth being nearly 40 miles and its speed $\frac{3}{4}$ of a foot per second. After passing Cape Farewell, it curves round to northward and follows the west coast of Greenland for some distance into Davis Strait. After having run for a few degrees in this direction it bends to the south-west, towards the coast of Labrador, along the whole length of wbich it rums, then proceeding to the south-east, enlarged by the polar current which comes from Baffin's Bay. On quitting Labrador, where its speed is $\frac{5}{6}$ of a foot per second, and its breadth 50 miles, the polar current on round ing the east coast of Newfoundland makes for the GuIf Stream, and, after doubling Cape Race, sends a branch to the south. west between the Gulf Stream and the American coast, which branch can be traced as far as Florida. As to the part of the polar current which does not take this route, it is generally ad. mitted that it flows underneath the Gulf Stream on the east of Newfoundland, and that it runs uninterruptedly to the south-east, towards the African coast, where the waters of the ocean are of a temperature comparatively low.

In order to explain the causes of these immense ocean currents by the aid of the laws of the movement of water in ordinary conduits, it is necessary first of all to know the forces which produce and maintain the movement of these currents. Captain Maury, who has made a special study of this question, has given it as his opinion that these ocean currents are due to the differences caused by the changes of temperature and of saltness in the specific gravity of the water of the sea. In order to make this theory more easy of comprehension, Maury imagines a globe like the earth covered over the whole of its surface with a sea 200 fathoms in depth, the water throughout being of the same density; at the same time he supposes the smrounding circumstances to be the same at all points, and that there being neither evaporation nor precipita. tion, there can of course be neither winds nor currents upon the imaginary globe. He next supposed the water contained between the tropics suddenly transformed into oil to a depth of 100 fathoms. From this moment the equilibrium is destroyed, and there results a general system of currents and counter-currents ; for the oil, being lighter than the water, will rush along the surface towards the poles, while the water of these regions makes for the equator in the shape of a submarine current. As the oil reaches the polar sea, it is supposed to be transformed into water, which returns to the equator, where it is changed anew into oil that again rises to the surface and again makes its way to the poles, and so on. If then this globe turns, like the earth, on its axis once in the twenty-four hours from west to east, each particle of oil, according to Maury, will procced towards the pole in a spiral course with a speed towards the east always in. creasing; on reaching the pole it will turn at a rate equal to that at which the earth revolves at the equator, viz., 225 miles an hour. But, says Maury, when the oil has been changed into. water, it will return towards the equator describing a curve in a westerly direction. If the sea in question should be bounded by land, as is the case on the surface of the earth, the uniformity of 
these currents will be broken up by different local clrcumstances; and the speed of the currents will vary at various places, but there will always be a system of equatorial and polar currents. Is it not admissible then to suppose, asks Maury, that the cold waters coming from the north and the warm waters issuing from the Gulf of Mexico and made lighter by the heat of the 1ropics, will act relatively to each other in the same way as the water and the oil in the preceding example?

The Gulf Stream was at one time regarded as a branch of the Mississippi ; but this notion must be abandoned since it has been proved that the volume of the Gulf Stream is many thousand times greater than that of the river, and that its water is salt, while the water of the Mississippi is fresh. Next, Benjamin Franklin's idea was generally adopted, viz., that the tradewinds drive the waters before them into the Carribean Sea, whence they issue more slowly in forming the Gulf Stream. Maury, however, refuses to accept this explanation; he admits that the trade-winds may increase the speed of the stream in the strait of Florida, but he maintains "that it is impossible for these winds to give such an impetus to the Gulf Stream as would make it traverse the whole of the Atlantic as a markedly distinct current. He caps his objections to the theory of Franklin by remarking, that as surely as a river flows along its bed only under the influence of gravity, so the course of the Gulf Stream in the midst of the ocean necessitates the existence of a never-ceasing moving force; in short, he says, if gravity did not exist, the waters of the Mississippi would never leave their source, and, were it not for a difference of specific weight, those of the Gulf Stream would remain for ever in the tropical regions of the Atlantic. But as Maury disputes the correctness of Franklin's statement, viz., that the surface of the sea is above the normal level in the Gulf of Mexico, and that the water tends by virtue of its weight to rush towards the north, and as observation has proved that along the western edge of the Gulf Stream there flows a current of those cold waters which descend southwards as far as Florida Strait, he can no longer maintain his first opinion as to the cause of the Gulf Stream. He is forced to resign the hypothesis that the water of the Gulf Stream, on account of its greater degree of saltness, has a specific gravity greater than the water of the polar seas, to which it flows in virtue of its great density, causing a current in a direction contrary to the lighter waters of these colder regions. But from the noment that Maury supposes that the ocean currents have their origin at the time when the water of the tropics is lighter, and that of the Gulf Stream heavier than the water of the Polar seas, his point of view becomes uncertain and difficult to sustain; and he fails all the more signally in presenting the question of the currents in its true light, from the fact that at that time there existed no exact method of obtaining the specific gravity of the water of the ocean, the degree of saltness of the different seas being then unknown.

(To be continued.)

\section{PHYSIOLOGY FOR WOMEN*}

BY Physiology we should understand a knowledge of the functions of the human body, and of the laws which regulate and maintain its various actions. The physiology of plants and of the lower tribes of animals (Botany and Zoology) are described by two other Professors in the University, and there will be little enough time for me to condense and give an account of what is now known of the subject, even as I have limited it. Whatever useful information, however, can throw light on human physiology, derived from every collateral science, will be made use of to assist inquiry. After some preliminary lectures on the histology, chemistry, the physical and vital properties of the tissues, I shall more especially dwell on the two great functions of nutrition and innervation. The former involves an acquaintance wih what constitutes a proper food for man-how it is prepared by mastication, insalivation, digestion, chymification, sanguification, and respiration, to form the blood; how out of this blood the tissues are formed; and how, after these have fulfilled their proper uses, they are separated from the body in the act of excretion. The latter comprehends a description of the functions of mind, including the mental acts, sensibility, sensation, volition, and the varied lsinds

* Abstract of the Opening Lecture of the Ladies' Course of Physiology, delivered in the University of Edinburgh, Nov, 2, by Prof. Bennett. of motion; of the functions of the nerves; of the special senses, such as smell, taste, touch, sight, hearing, and the muscular sense of voice and speech ; and lastly, of sleep, dreams, somnambulism, catalepsy, trance, witchcraft, animal magnetism, \&c. \&c. Of the subjects included under these heads it is impossible to overrate the importance in reference to their relation to the health and happiness of man, his physical and moral welfare, his social relations, his national resources, and the prosperity of his race. I have long formed the opinion that physiology, besides being essential to the medical student, should be introduced as an elementary subject of education in all our schools - should be taught to all classes of society. It is an ascertained fact that I00,000 individuals perish annually in this country from causes which are easily preventible, and that a large amount of misery is caused by an ignorance of the laws of health. The clergy should especially study it-first, with a view of diminishing the difference in thought existing between literary and scientific men; and, secondly, because their influence on the people from the pulpit, and as parish ministers, is so important. All other professions and trades, however, might beneficially study physiology, especially newspaper editors and reporters, who diffuse a knowledge of useful things among the public; and architects, who have not yet learnt to build dwelling-houses and public halls properly ventilated. But women, in all classes and degrees of society, have more to do with the preservation and duration of human life even than men. It has been argued that, inasmuch as even the brutes know instinctively how to take care of their young, so must women be able to do the same. But the human infant is the most helpless of creatures, and nothing is more lamentable than to witness the anxieties and agony of the young mother as to how she should manage her first-born. In no system of education are women taught the structure and requirements of the offspring which will be committed to their charge; and certainly no error can be greater than to suppose that the senses and instincts are sufficient for teaching man as to his physical, vital, and intellectual wants. The enormous loss of life among infants has struck all who have paid attention to the subject, and there can be no question that this is mainly owing to neglect, want of proper food or clothing, of cleanliness, of fresh air, and other preventible causes. Dr. Lankester tells us, when ably writing on this topic, that, as coroner for Central Middlesex, he holds one hundred inquests ammually on children found suffocated in bed by the side of their mothers, and he calculates that in this way 3,000 infants are destroyed in Great Britain annually alone, attributable in nine cases out of ten to the gross ignorance of those mothers of the laws which govern the life of the child. * But women are the wives and regulators of the domestic households. They also constitute the great mass of our domestic servants. On them depends the proper ventilation of the rooms, and especially the sleeping rooms, in which all mankind on an average spend onethird of their lives. Children are too often shut up all day in crowded nurseries, and when ill, are subjected to numerous absurd remedies before medical assistance is sent for. Their clothing is often useless or neglected, the dictation of fashion rather than of comfort and warmth being too frequently attended to. The cleanliness of the house also depends on women, and the removal of organic matter from furniture and linen, the decomposition of which is so productive of disease. Further, the proper choice and preparation of food is entrusted to them,- -all these are physiological subjects, the ignorance of which is constantly leading to the greatest unhappiness, ill health, and death. Among the working classes it is too frequently the improvidence and ignorance of the women which lead to the intemperance and brutality of the men, from which originate half the vice and crime known to our police offices and courts of justice. Additional arguments for the study of physiology by women may be derived from the consideration of-(I) the effects of fashionable clothing - the tight lacing, naked shoulders, thin shoes, high-heeled boots-often subversive of health; (2) the great objects of marriage - the production of healthy offspring-and all the foresight, care, and provision required, but too often neglected through ignorance, to the danger both of mother and child; (3) the proper employment of women, which should be regulated with regard to their conformation and constitutions; and (4) nursing the sick, which is one of the most holy occupations of women, and which would be much more intelligently done if

* See his excellent pamphlet, "What shall we Teach; or Physiology in Schools." London: Groombridge \& Sons, $x 870$. 